Revista de Estudios Taurinos

N. ${ }^{\circ} 12$, Sevilla, 2000, págs. 89-120

\title{
TOROS Y SOCIEDAD EN LIMA COLONIAL
}

\author{
Fernando Iwasaki Cauti \\ Universidad Católica del Perú
}

«La propensión de los Españoles á las corridas de toros es igual en toda la extensión de los dominios de S.M., y en esta capital regularmente gustan de semejante entretenimiento» Manuel de Amat y Juniet, Memoria de Gobierno.

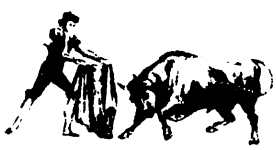

pesar de estar situado en la periferia del mundo hispano, el Perú es un país donde la fiesta brava ha conservado todo su hechizo y vigor desde los primeros años de la dominación española. Sin embargo, a despecho de la abundante documentación existente, nunca se ha realizado una investigación que se aparte de los daguerrotipos costumbristas y anecdóticos que han reducido el tema a un deleznable «archivo de criollismo».

Nuestro trabajo pretende seguir el itinerario del toreo en Lima desde la fundación de la ciudad en 1532 hasta la construcción de la Plaza de Acho en 1766, para explicar cómo se articularon poder y sociedad alrededor de la fiesta durante los 300 años del virreinato peruano. Evidentemente será una panorámica preliminar, pero a la vez trazaremos los derroteros que otros investigadores podrán recorrer en posteriores estudios. 


\section{1.- DEL JINETE SEÑORIAL A LOS NEGROS CAPEADORES}

Según eruditos autorizados, la primera corrida celebrada en Lima se llevó a cabo durante la consagración de óleos hecha por el obispo fray Vicente de Valverde el 29 de marzo de 1540:

«La función fue en la Plaza Mayor; principió a la una de la tarde, y se lidiaron tres toretes de la ganadería de Maranga. Don Francisco Pizarro, a caballo, mató al segundo toro a rejonazos» (Palma, 1957: 46-47).

La cita anterior exagera cuando menos dos detalles. El que Pizarro pudiera rejonear a caballo con más de setenta años de edad y, lo más curioso, que se hable de una «ganadería de Maranga». Con respecto a lo primero ningún biógrafo del conquistador del Perú recoge semejante acontecimiento, y en cuanto a lo segundo debemos apuntar que Nicolás de Ribera el Mozo, encomendero de Maranga, en efecto era propietario por esos años de un valioso hato de vacas valorado en ocho mil pesos (Lohmann, 1983: II, 265). Pero además hay que corroborar que también era un empedernido aficionado pues, en 1564, elevó una instancia al Rey en la que se quejaba por el desenlace de una corrida (A.G.I., 15.V.1564: 121).

Sin embargo, no hay que olvidar que los escasos estancieros de la época debieron ser a la vez regidores o alcaldes, en cuyo caso resultaban ser los primeros beneficiarios de la fiesta, ya que no sólo eran quienes se lucían alanceando toros, sino también, serían los dueños de las reses lidiadas. Cada celebración exaltaba su prestigio y poder: 
«Los principales colonos, como individuos, exigían tierras; como regidores eran responsables de la distribución de las tierras. Como rancheros producían carne de vaca y algunas otras provisiones con que se alimentaban las ciudades; como regidores fijaban los precios a que se debían vender las mercancías... los cabildos fueron las instituciones principales para salvaguardar los intereses y expresar las opiniones de la clase conquistadora» (Parry, 1970: 82).

Durante el siglo XVI el número de toros bravos o encastados en Lima debió ser más bien raquítico, razón por la cual «el cabildo destinó para esta diversión cuatro días en cada año; y desde 1559 se verificaron, la primera corrida el día de la Epifanía o Pascua de Reyes, la segunda el de San Juan, la tercera el de Santiago y la cuarta el de la Asunción» (Mendiburu, 1902: 83-84). Sin embargo, también hay que tener en cuenta la prohibición papal, recurrida por el rey y origen de no pocas disputas entre el poder civil y el clero. De ahí que el virrey Toledo le dirigiera al monarca estas líneas:

«Entre otros breves en que acá nos bamos retiniendo hasta entender que estén pasados por Vuestra Alteza como Su Magestad lo manda, a cido uno el de los toros, en que la pobreza y melancolía de estas tierras recibió muy mal que el Arzobispo le hiziese publicar, no aviéndose hecho en esos reynos después de aver suplicado dél. La ciudad embía su suplicación y la mía también, porque el dicho breve habla con los governadores. Vuestra Alteza mandará que se siga la causa como más conviniere y fuesse servicio de Su Magestad y me mandará avisar de lo que sobre ésto se uviere de hazer» (A.G.I., 1571: 28-A).

Al parecer, las gestiones del virrey fueron eficaces porque los toros volvieron a correrse en Lima ese mismo año, pero el arzobispo Loayza insistió en su rechazo ante la Corona, mas en esa ocasión alegando la integridad de los indios. La preocupación del dominico significaba además que la 
lidia peruana convocaba a otros actores que no eran exclusivamente de la nobleza:

«En esta yglesia se leyó el propio motu de su Sanctidad sobre la prohibición de los toros estando el virrey en ella. Después de leyda me dijo el virrey que por mandado de Vuestra Magestad se avía consultado al Papa sobre ello y que se podían correr toros hasta que viniese la respuesta de su Sanctidad. El cabildo desta ciudad apeló o suplicó della arrimándose a la suplicación o consulta que por mandado de Vuestra Magestad se hizo, córrense toros como antes. Suplico a Vuestra Magestad mande lo que se ha de hazer en ello. Más peligro e ynconveniente ay en esta tierra por causa de los yndios que en ese reyno, porque, como los toros se corren en fiestas y en tales días los yndios suelen beber demasiado, demás de ser gente torpe, hieren y matan algunos, y, aunque se ha proveydo que no salgan yndios a la plaza, no se puede guardar enteramente» (A.G.I., 23.IV.1572: 300).

¿Qué significaba la presencia de los indios durante la lidia? Desde los tiempos de Pizarro hasta el gobierno del marqués de Cañete (1555-1561), los jinetes se dividían en dos bandos para rejonear toros o jugar a las cañas, pero «después de ellos fue cuando se introdujeron en la corrida cuadrillas de parlampanes, papahuevos, cofradías de africanos y payas» (Palma, 1957: 47). Como se puede apreciar, desde muy temprano indios y negros se integraron a la fiesta.

En un primer momento la función de los negros debió ser más bien discreta, pero los indios alcanzaron rápido protagonismo a través de la suerte de moharras (Fig. n. ${ }^{\circ} 14$ ):

«Conocíase por lance de moharras el esperar al toro cuatro ó seis indíjenas, por lo regular muy ébrios, que armados de rejones cortos, apoyados en el suelo, y sentados ó echados, llamaban ó provocaban al toro con unas pequeñas capas encarnadas. Algunos morían en su empeño de perseguir á la fiera y hostilizarla por muchas veces: el toro 
pasaba sobre los tales hombres ó levantaba en el aire a los que podía» (Mendiburu, 1902: 90) ${ }^{1}$.

Entrado el siglo XVII, las celebraciones aumentaron en número según la calidad de los acontecimientos, lo que complicó la etiqueta y protocolo de las corridas, desatando conflictos entre las autoridades ${ }^{2}$. Tenemos el caso del encierro conque

${ }^{1}$ Esta suerte se mantuvo en Lima hasta los primeros años del siglo XX, pero un cronista del siglo pasado la describe así: "Otra de las suertes propias del Perú es la de mojarras. Varios indios llamados mojarreros, se arman con largos chuzos con puntas de fierro: échanse en el suelo, para recibir al toro, y cuando este embiste al grupo, pretenden los indios clavarle el chuzo por donde puedan. Muchas veces pasa el toro, pisando á los mojarreros; muchas veces toma á uno de ellos en las astas y lo pelotea; pero el indio no se rinde y es preciso que quede gravemente herido para que no vuelva á la carga. El mojarrero no sale al circo mientras el toro no se le presente de la corpulencia de un perro; y llega á realizar ese fenómeno óptico, no á favor de lentes cóncavos, sino á fuerza de tomar aguardiente. Desde que da principio la corrida empiezan los indios á beber; unos á otros se preguntan de qué tamaño está el toro y los que aun no tienen la vista en el grado necesario contestan: «Todavía está grande; echa otra copa. ¿Cuál era y cuál es, hoy mismo, la mejor corrida de toros? No aquella en que los toreros habían manifestado mayor destreza, ni las fieras mayor bravura. Los aficionados necesitan mayores y más fuertes emociones. Si salían del circo unos cuantos caballos muertos ó, cuando menos gravemente heridos; si había toreros estropeados; si los indios mojarreros habían volado por los aires á impulso de recias testaradas, en una palabra, si había sangre y golpes la tarde era lucida, y si había una muerte, ¡completa! ¡soberbia!» (Cif. Fuentes, 1867: 144-145).

2 «Además de las fiestas ordinarias de toros que se dirigían por empresarios sujetos á contrato con la ciudad, había otras que disponía el Cabildo, en la que sus agentes se entendían para consultar el mayor decoro y lucimiento. Eran estas las que se hacían con ocasión de la jura del Rey, nacimiento de Príncipe, matrimonios reales, entrada en Lima de nuevo Virrey ó Arzobispo, y fundaciones ó acontecimientos plausibles, como lo fueron la canonización de Santa Rosa y de otros Santos. También se hacían funciones extraordinarias de toros que carecían del aparato de aquellas, siendo asimismo inferiores en todo á las de costumbre en cada año, tales como las que costeaban los que recibían el grado de Doctor en la Universidad de San Marcos» (Mendiburu, 1902: 84). 
el nuevo virrey deseaba agasajar a su antecesor en 1629, pero ya preparada la plaza se tuvieron que retirar los tablados

«por estar ocupado y no hallar lugar conveniente que dar a su antecesor, porque en el acuerdo el señor Virrey trató de que combidaría al señor Marqués de Guadalcázar que le daría su mano derecha, pero respondió el Presidente o Oydor más antiguo de la Real Audiencia que en manera ninguna consentiría que se le quitase su lugar, que es el primero después del Virrey» (Suardo, 1938: 6).

El arzobispo de Lima no pensó lo mismo en 1674, ya que para celebrar su llegada organizó una corrida y se instaló en los balcones del cabildo «y no salió a las ventanas del acuerdo ningún señor oidor a verlos. Tampoco hubo paseo por la plaza de alcaldes ordinarios, ni un caballero que saliese a ella por el disgusto de los señores oidores que querían ir a verlos a Cabildo» (Mugaburu, 1935: 169). Veinte días después se corrieron toros en honor del virrey «y el señor Arzobispo no salió a verlos» (Mugaburu, 1935: 170).

$\mathrm{Y}$ es que por aquel entonces la fiesta seguía siendo un atributo señorial, como lo demuestra la crónica de una corrida celebrada el 6 de noviembre de 1674, donde el número de caballos expresa a las claras el patrimonio y status de los jinetes:

«Esta mesma tarde, a las tres, salió de Palacio el señor Virrey y la señora Virreina en su carroza nueva y con su silla de manos detrás, con mucho acompañamiento, y dió vuelta a toda la plaza, que estaba toda ella cercada de tablados y aforrada de tablas, al uso de la Corte, y coronada toda de gente; y se fueron a la galería de Cabildo a ver correr los toros. Don Miguel de Oruña y don Francisco de León entraron en la plaza de Lima en carroza y con catorce caballos detrás, los ocho del capitán León y los seis de Oruña, y con sus espadas anchas y muchos rejones.

»Al primer toro que salió dió Oruña dos rejonazos muy buenos y limpios; y en el discurso de la tarde dió otros seis rejonazos, y los toros le hirieron muy mal dos caballos. 
Don Francisco de León dió cuatro rejonazos y los toros le hirieron cuatro caballos y él hirió otro caballo en que iba con su espada ancha por dar al toro. Ya tarde lo sacó de la silla un toro y a pie se fué al toro con su espada ancha en la mano y cara a cara le embistió; y el toro lo arrojó en el suelo y lo maltrató, que le lastimó en la cara del golpe.

Don Rodrigo de Mendoza entró sólo en la plaza, de aventurero, en su caballo, con dos pajes y dos rejones y los empleó bien, y salió muy airoso, sin mudar caballo y con muchos vítores» (Mugaburu, 1935: 177).

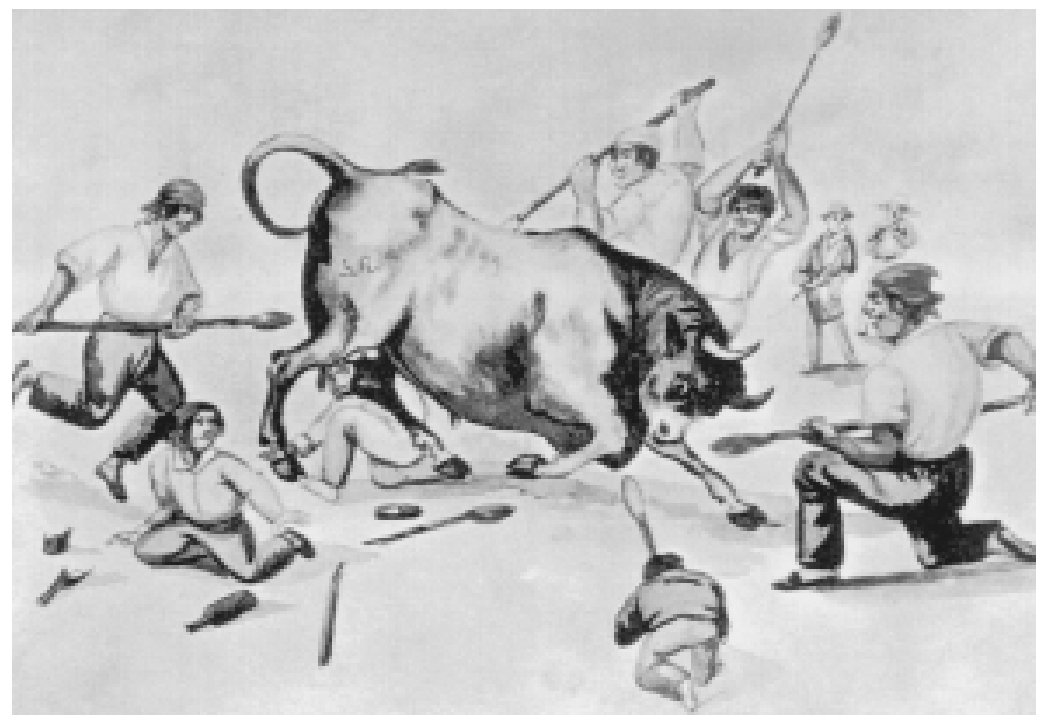

Fig. n. ${ }^{\circ}$ 14.- Pancho Fierro: Suerte de la Moharra, 26 x 20,5 cm, acuarela, Lima, Museo Taurino de Arte (Berckemeyer, 1966: 49).

Sin embargo, poco a poco esos «pajes» y auxiliares fueron acaparando el protagonismo, quienes al lado de los indios consiguieron darle otro color a las corridas. Un curioso cartel de 1630 da cuenta de las diversas suertes que se llevaban a cabo en las fiestas de la plaza de Lima (Fig. n. ${ }^{\circ}$ 15): 


\section{PREMIO}

PREMio Que la Hermandad de SAN Eloy [PLATERos] REPARTE EL MARTES QUE VIENE A LAS PERSONAS QUE MEXORES SUERTES HIZIESEN EN LAS FIESTAS DE TOROS CONFORME AL CERTAMEN.

«Al Cavallero QUe Mexor lanzada diere al TORO, SE LE DARÁ UNA PIEZA DE AgUa CON SU SALVILla DORAda Y ESMALTADA. Segundo: Al CaVallero Que mayor dificultad hiziere a CaVallo, SE LE DARÁ UN BERNEGAL DE PLATA BLANDO GRANDE.

\section{A los Cavalleros de Rejón}

Primero: una pieza de agua con salvilla dorada. Segundo: una canastilla de plata.

TERCERO: Dos CANDELEROS CON PLATILlos. QUARTO: DOS CANDELEROS CON PLATILLOS.

QUinto: UNA PIEZA DE AgUA BLANCA.

SEXTO: OTRA PIEZA de lo Dicho.

\section{A los Cavalleros Jinetes}

Primero: Al que mexor corriere y más ayroso anduviere en la PLAZA SE LE DARÁ UNA PIEZA DE AGUA BLANCA ACASTAÑAda.

Segundo: Una pieza de agua CON PIÉ.

TERCERO: UNA TEMBLADERA CON ASSAS.

A los Cavalleros galanes

UnA TAZA DORAda de PLAta.

Dos CANDEleros de platillos.

UNA PIEZA DE AGUA CON PIÉ.

Al Cavallero que con más desayre Corriere se le dará una higa DE CRISTAL GUARNECIDA EN ORO.

\section{A la Gente de á pié}

«A las PERsonas Que CON REXoncillo MATAREN al toro SE LE dará EL TORO Y UN POMO DE PLATA. -DOS LO MisMo. -TRES LO MisMo. -QUATRO LO MISMO.

A LOS QUE MEXORES SUERTES HIZIEREN AL TORO SE LES DARÁ UN POMO DE PLATA A CADA UNO HASTA DOCE Y EL QUE DEXARRETARE AL TORO PIERDE EL PREMIO.

Son Jueces de los premios los señores don diego de Carvaxal, Correo Mayor, don francisco Mesia y don Bartholomé de Osnayo, Contador desta Real Caxa (Suardo, 1938: 96-98). 
Hay dos cosas que merecen resaltarse en el mencionado cartel anterior. En primer lugar, la participación de «gente de a pie», cuya premiación por «las mexores suertes que hizieren al toro» indica la existencia de ciertos cánones o criterios a calificar que existían en Lima desde el siglo $\mathrm{XVII}^{3} \mathrm{y}$, en segundo término, que la corrida en cuestión era organizada por el gremio de plateros, por lo tanto, al margen de las fiestas oficiales del cabildo. ¿Era común que los oficiales y artesanos de la ciudad festejaran con toros sus días patronales?

Siguiendo los diarios de Suardo y Mugaburu, que apenas cubren algunos años del siglo XVII y de manera arbitraria, podemos encontrar muchas referencias sobre encierros organizados por los gremios y otros colectivos, que suponemos debieron ser, lo suficientemente memorables como para haber sido consignados por los curiosos escribientes:

« 8-VII-1630: Gremio de plateros: «se jugaron toros con mucho regocijo» (Suardo:70).

6-X-1630: Gremio de confiteros, «mandaron jugar toros que fueron muy buenos» (Suardo, 92).

6-XII-1630: Gremio de plateros, torneo (Suardo, 102).

13-XII-1630: Gremio de herreros: «mandaron jugar toros en esta plaza que fueron razonables» (Suardo, 103).

19-XII-1630: Gremio de mercaderes: «mandaron jugar toros, los quales a dicho de todos, han sido los mexores que hasta agora se han jugado» (Suardo, 103).

22-II-1631: Universitarios, «mandó jugar toros que fueron generalmente muy buenos y muy regocijados» (Suardo, 119).

9-XII-1656: Gremio de plateros, «hubo toros muy bravos» (Mugaburu, 26).

29-IX-1659: Gremio de bodegueros, «salió un toro con un enjalma que tenía artificio de fuego» (Mugaburu, 33). el siglo XVIII.

${ }^{3}$ En España las faenas de a pie adquirieron carta de ciudadanía recién en 


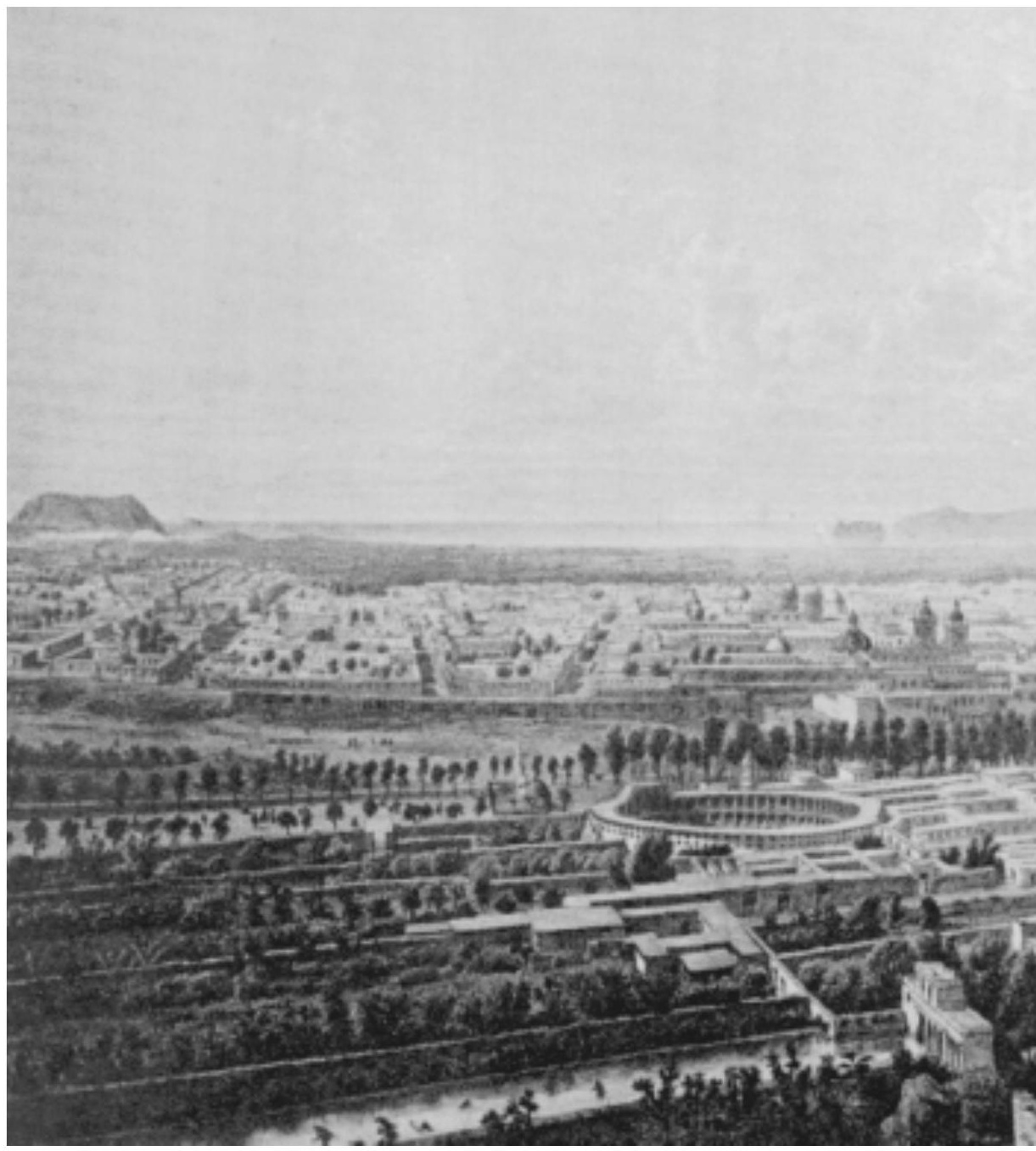

Fig. n. ${ }^{\circ}$ 15.- Batta Molinelli: Panorama de Lima dedicado a la Honorable Municipalidad, litografía, Lima, Museo Taurino de Arte. En esta página, a medio plano, se distingue la plaza poligonal de Acho, levantada en 1766, por el alcalde Agustín H. de Landíburu, donde se celebra 


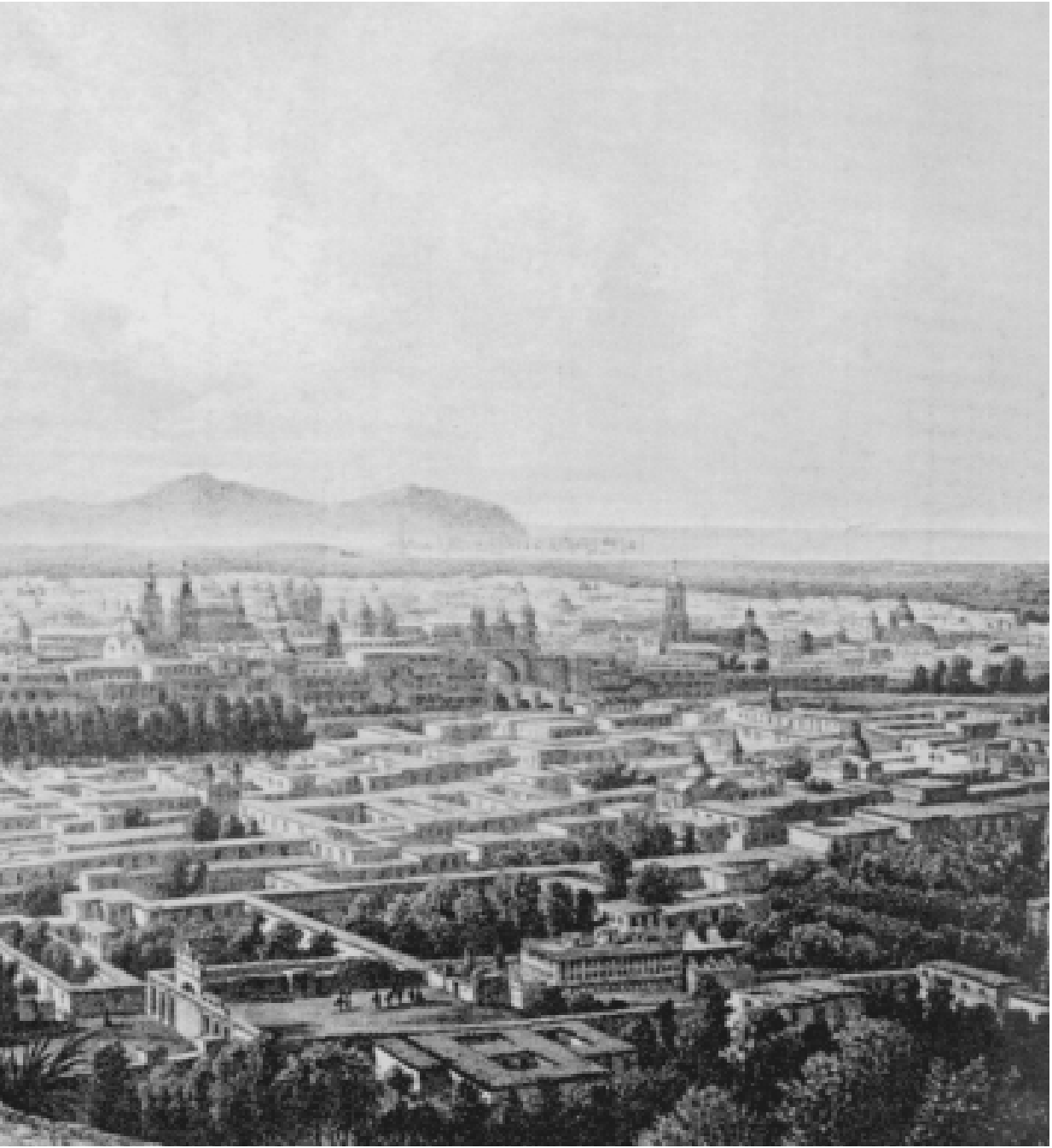

la Feria del Cristo de los Milagros. En 1982, se inauguró una segunda plaza, llamada «Sol y sombra», en el barrio de la Victoria para albergar la Feria de Santa Rosa, la venerada patrona de Lima (Berckemeyer, 1966: 69). 
2-XII-1659: Gremio de pintores, «y hubo toros el resto de la tarde muy bravos» (Mugaburu, 34).

29-XII-1659: Gremio de plateros, «Hubo toros la mesma tarde y rejonearon cuatro que salieron como grandes de Castilla» (Mugaburu, 34).

22-X-1681: Soldados de la Guardia, «y fueron muy bravos porque los soldados fueron por su cuenta a diferentes parajes a comprarlos» (Mugaburu, 217).

8-VII-1683: Gremio de carpinteros, «fueron muy bravos» (Mugaburu, 226)» (Suardo, 1938 y Mugaburu, 1935).

Es interesante comprobar cómo en un sólo año podían realizarse cinco corridas aparte de las cuatro programadas por el Cabildo. En esas fiestas los indios y negros pudieron ir incrementando su participación, ya que estaban perfectamente integrados a los gremios (Iwasaki, 1989; 125-136; 150-163). No obstante, tímidamente, los negros comenzaron a ganar terreno en los encierros y, en enero de 1631, ya celebraron su primera corrida:

«A 14, los morenos hicieron sus fiestas al nacimiento del Príncipe Nuestro Señor y mandaron, por la tarde, jugar toros, que no fueron muy buenos pero fueron de mucho gusto y risa para todos, porque salieron hasta 30 negros a la plaza con capas y gorras milanesas a jugar los toros, que hicieron figuras muy ridículas y algunos dellos hicieron algunas suertes de consideración en dar garrochones, con que la fiesta vino a ser de mayor gusto que todas» (Suardo, 1938: 108-109).

«Evidentemente se trataba de una farsa montada por los mismos amos, quienes ignoraban el impredecible desenlace que sobrevendría años después. De hecho, no sólo los negros tenían sus fiestas, pues en febrero de 1631 los mulatos representaron La Ilíada por las calles de Lima y "a 11 por la tarde los mulatos por remate de su fiesta jugaron toros"» (Suardo, 1938: 116).

Debe entenderse que un negro disfrazado de Agamenón o Aquileo, habría causado la misma hilaridad en cualquier anillo taurino. La clase dominante toleraba y promovía esas paro- 
dias que, a la larga, adquirieron carta de ciudadanía. Es posible que en esos lances se gestara el capeo a caballo, suerte genuinamente peruana y que ha sobrevivido hasta nuestros días (Fig. n. ${ }^{\circ}$ 16). De hecho, en diciembre de 1656 el Diario de Mugaburu consigna: «Martes diez y nueve del corriente, los negros criollos jugaron toros en la plaza; y hubo rejones y rompeleño. Tarde regocijada» (Mugaburu, 1935: 27).

Mientras tanto, los indios siguieron integrándose a las corridas a pesar de las disposiciones en contra ${ }^{4}$, y así, hacia 1659, la población andina logró celebrar su propia fiesta en la capital del virreinato, honrando la memoria de los incas y esquivando la muerte entre los cuernos de los toros:

«Martes 23 del dicho mes hicieron la fiesta los indios, donde hubo un castillo en la plaza, y salió el rey Inga y peleó con otros dos reyes hasta que los venció y cojió el castillo; y puestos todos tres reyes ofrecieron las llaves al Príncipe que iba en un carro retratado; y salieron a la plaza todos los indios que hay en este reino, cada uno con sus trajes; que fueron más de dos mil los que salieron, que parecía la plaza toda plateada de diferentes flores, según salieron los indios bien vestidos y con muchas galas. Hubo toros aquella tarde y salieron dos indios a garrochear a los toros. Fiesta de mucho regocijo para todos, y dicen llevaron la gala de todos, con que cesaron las fiestas (Mugaburu, 1935: 34-35).

Al término del siglo XVII, indios y negros estaban completamente asimilados al mundo taurino del virreinato, pero antes de alcanzar el protagonismo definitivo los toros pasaron a ocupar el lugar que se merecían en la fiesta. Así lo demuestra el primer listín impreso aparecido en Lima:

4 «A 15 [de 1630], por aver hecho relación a Su Excelencia el protector general de los naturales que en el hospital de Santa Ana estavan muchos de ellos muy maltratados de los toros, se pregonó un bando para que los días que se jugasen toros en esta ciudad ninguno dellos pueda estar en esta plaza bajo pena de cinquenta azotes» (Suardo, 1938: 94). 
RAZÓN INDIVIDUAL DE LOS TOROS QUE, EN DOS TARDES, SE HAN DE LIDIAR EN ESTA PLAZA MAYOR, EN OBSEQUIO A LA AUGUSTA PROCLAMACIÓN DE SU MAJESTAD DON FELIPE Y NUESTRO SEÑOR

ENCIERRO-PRIMERA MAÑNANA

EL ROMPE-PONCHOS, AZAHARITO

El Zoquete, RABón, COLORADO

El GALlareta, OVERo, DE

TARDE PRIMERA

EL FLOR DE CUENTA, CAPIROTE

El Diafanito, hosco, DE

El Pichón, blanco, de Gómez

El LAGARTiJa, GATEADO, DE

EL FLORIPONDIO, BARROSO, DE CHINCHA

El DESEADo, Alazán, tostado, DEL NARANJAL

El Chivillo, prieto, de

Chuquitanta

EL LECHE Migada, DE VILCAHUAURA

El PARTERo APAREJADO, BLANCO

EL INVENCIBLE, RETINTO
ENCIERRO-SEGUNDA MAÑNANA

El Patuleco, barriga blanca de OQuendo. de Casablanca

El Carasucia, gateado, de Bujama. Pasamayo

el potroso Lúcumo, de Huando. Contador

TARDE SEGUNDA

EL RASCA Moños, bLANCO, de Palpa. Lurinchincha

El PUCHO A LA OREJA, FRAZADO, LARÁN. de Chancaillo

El SACA CANDELA, FRONTIZO, DE HiLARIón

El Gato, gateado, del Pacallar ESQUIVEL.

EL ANTEOJITO, BRONCADO, DE MaLA

EL CORRE BAILANDO, CUlimosqueado de SAYÁN

EL LONGANIZA, PRIETO, DESPARRAMADO de Corral Redondo

El Diablito Cojo, Pintado, DE HeRVAY

El SACRistán, AJISEco, de Limatambo PRIETO, DE RETES

El Come Gente, overo PINTAdo

(Bujama de Quipoco, Palma, 1957: 48) 
Es obvio que la promoción de los hierros era, a la vez, un medio empleado por los hacendados de la aristocracia criolla para hacer alarde de su poder, pero tampoco se puede negar que hubo, dentro de ese sector, un decidido grupo de defensores de la fiesta. El siglo XVIII produjo en España muchos detractores de las corridas de toros, quienes impregnados del pensamiento dominante de la época no supieron encajarlas dentro del utilitarismo y las corrientes naturalistas de aquel entonces. Sin embargo, las metrópolis hispanoamericanas reaccionaron contra esas críticas y en algunas ciudades aparecieron alegatos en favor de la lidia.

En 1761, el oidor limeño Pedro Joseph Bravo de Lagunas, publicó un opúsculo sobre los derechos y exoneraciones del hospital de San Lázaro, en el cual incluyó una disertación sobre «los juegos de toros». Refiriéndose a esta circunstancias Mendiburu señala en sus Apuntes Históricos, que:

«Censuróse en Lima que se hiciesen corridas de toros con motivo de fiestas ú objetos religiosos y de piedad, y tal fué la causa que excitó al doctor Bravo [de Lagunas] á emplear su elocuente pluma en no pocas páginas de aquel folleto, para justificar su concepto y parecer afirmativo en favor de las lidias de toros. Defendió la cuestión con esmero y brío, sin renunciar [a] razón ó fundamento histórico que conviniese á su propósito. Él combatió las opiniones de los teólogos Suárez y Concino y del historiador Mariana. Contradijo las del cardenal Jiménez de Cisneros, y sin negar que el juego de toros fué muchas veces reprobado y prohibido, registró multitud de hechos y concesiones en sentido contrario, y no pocas resoluciones de los Pontífices permitiendo ese regocijo y dándolo por lícito y sano, ó derogando censuras y disposiciones restrictivas á instancias de los monarcas españoles.

»Recorrió asimismo todo lo que otros moralistas, y no pocos jurisconsultos, adujeron en apoyo de la diversión de toros, acostumbrada en Espana hasta para celebrar los grados de la Universidad de Salamanca, cuyo ejemplo sirvió á la de Lima para practicar lo mismo, autorizándolo en sus constituciones. 
»En esta disertación histórica, el magistrado partidario ardiente del juego de toros discutió la materia hasta donde le alcanzaron sus fuerzas, ó mejor dicho, hasta dejarla agotada. Defendiendo que aún podía hacerse promesa ó voto de lidiar toros con fines religiosos y caritativos, citó algunos casos y copió una Real Orden dirigida al Virrey del Perú marqués de Mancera, en la cual consta que el Cabildo de Lima representó al Rey que las fiestas votivas, como la de la Purísima, Santa Isabel y otras, se celebraron con toros, y que el Virrey conde de Chinchón lo había estorbado á merito de hallarse prohibido por breves pontificios; y que habiendo suplicado al Rey hiciese merced de mandar continuar aquella usanza, lo concedió así "para que los habitantes de Lima no se desalentasen ni disgustasen"» (Mendiburu, 1902: 92-93) ${ }^{5}$.

Sin embargo, los aristócratas no fueron los únicos aficionados, ya que en las afueras de Lima «reuníanse muchos individuos de la plebe, y sin escusar gastos hacían en cualquier paraje de la ciudad un simulacro de toros en que se veían banderillas, capeo, suertes de espada, etc.; formaban su toril, había juez, boletos y otras particularidades» (Mendiburu, 1902: 93).

Estos «individuos de la plebe» no eran otros que los negros y los indios, quienes organizaban sus fiestas a pesar de los privilegios concedidos a los dueños de la Plaza de Acho:

«De este incidente dio cuenta el Fiscal Protector General de Naturales de la Audiencia de Lima, acompañando la representación que le hizo el Procurador del Común de Yndios del referido pueblo de Lurín, con inclusión de los decretos expedidos por el Virrey en 1 y 11 de setiembre de 1793, por los quales declaró que sin ofensa del privilegio exclusivo concedido al asentista de la Plaza de Lima, pudiese

5 Bravo de Lagunas ya había publicado en 1755 su Voto Consultivo, verdadero manifiesto de la vocación monopólica de los latifundistas limeños. Ver Iwasaki (1987: 133-162). 


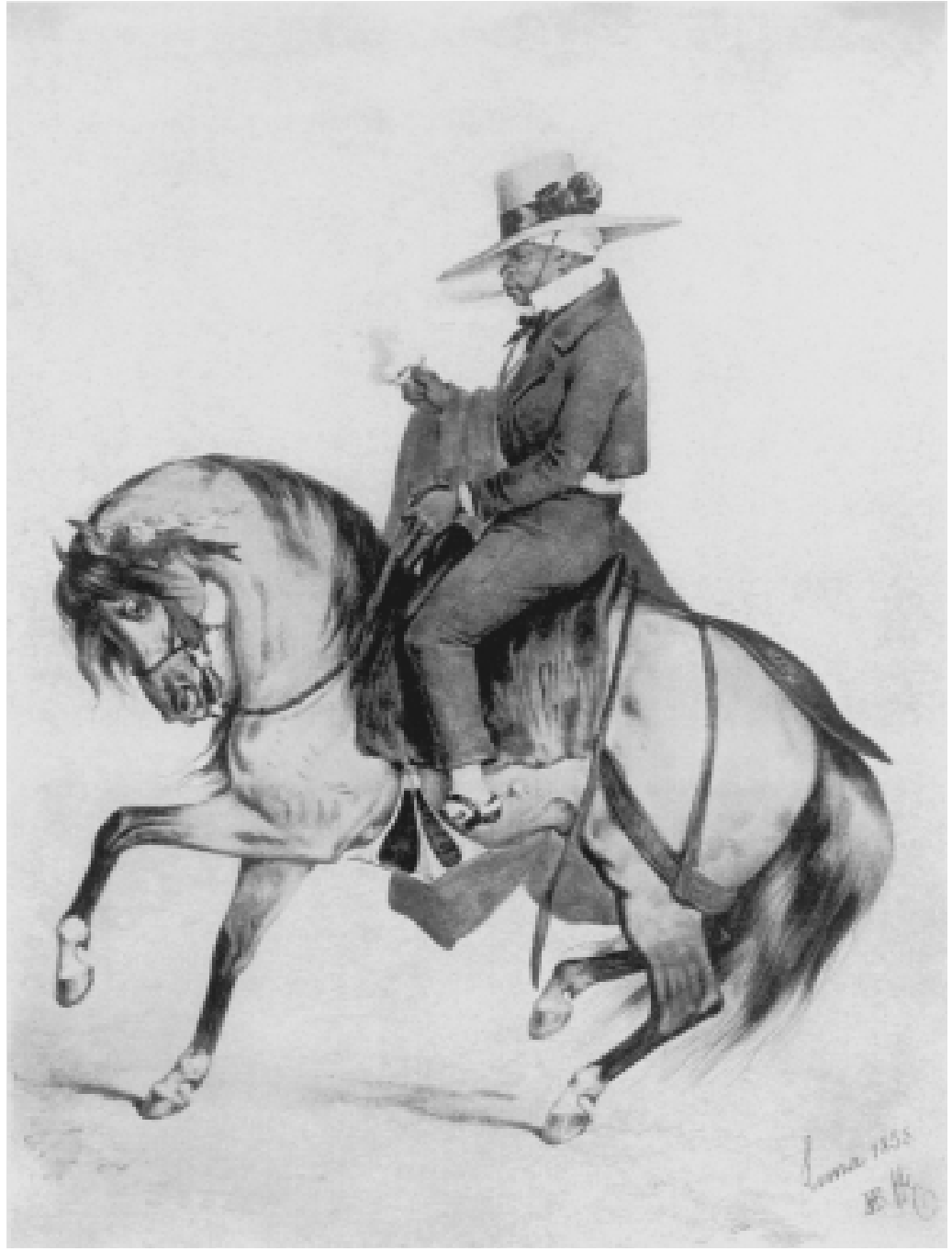

Fig. n. ${ }^{\circ}$ 16.- Bonnaffé: Torero a caballo: el Capeador, litografía, Lima, Museo Taurino de Arte (Berckemeyer, 1966: 47). 
dicho pueblo correr las lidias que acostumbraba del ganado que havía en las lomas en los días de celebridad de su Patrono San Miguel, con tal de que no se corriesen ni matasen toros en ellas. Así, porque siendo diversión permitida a todo aficionado y gente inexperta, podía haber alguna desgracia, como porque se inutilizaban los toros con los resavios que adquirían en las lides, por cuyos motivos sólo debían correrse novillos, bueyes y bacas» (A.G.I., 14.IX.1798).

Empero, conforme avanzaba el siglo XVIII aumentaba también la demanda de los servicios de los negros para los encierros en la Plaza de Acho. Una queja de la propietaria del coso limeño nos revela sus tribulaciones como empresaria, pero además que los negros criollos ya cobraban por su trabajo como peones o lidiadores:

«El mal tratamiento que sufre la plaza es mucho mayor del que paresce, y desde luego protesta la suplicante a V. Excelencia que sus desembolsos han sido grandes para reponer los daños causados en las corridas del carnaval. Si en éstos se van las cortas utilidades de la plaza, no tendrá la suplicante cómo satisfacer el travajo que se impende en esta negociación... Con decirle a V. excelencia que no hay [día] del año en que no se travage para las corridas de toros; que no hay yndio baquero que no quiera enojar y molestar a la suplicante; que todos los negros y zambos se le esquivan y huyen para ser rogados y bien pagados; que el que quiere la engaña con la pericia que no tiene y que el hermano de la suplicante necesita andar hecho un peregrino de hacienda en hacienda y de valle en valle buscando toros, en cuyos precios recive la ley y sufre el perjuicio de que resulten malos los que en las pruevas parecieron buenos (A.G.I., Lima, 7.IV.1788: 968).

En 1790, esos negros toreros que huían «para ser rogados y bien pagados», hicieron su ingreso triunfal a la Plaza de Acho, porque los alguaciles y alcaldes ordinarios:

«Iban seguidos de doce toreros con capas de terciopelo y tisú, doce arlequines ridículamente vestidos y con variedad de colores, dos 
conductores de las desjarretaderas, y dos que llevaban el puesto de garrochas: unos y otros con monteras de terciopelo con láminas de plata, en las que estaban grabadas las armas del Rey y las de la ciudad» (Mendiburu, 1902: 83-84).

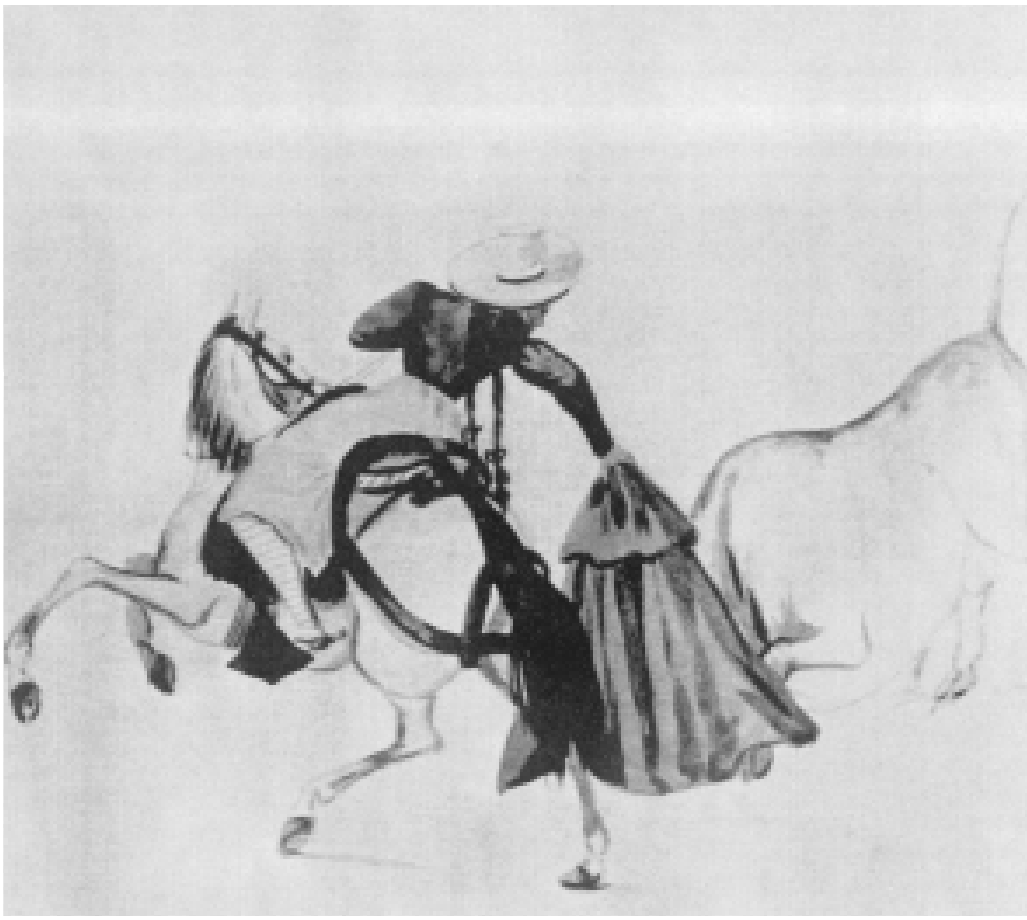

Fig. n. ${ }^{\circ}$ 17.- Anónimo (87): Mujer toreando a caballo, acuarela, Lima, Museo Taurino de Arte (Berckemeyer, 1966: 50).

Mientras se extinguía el jinete señorial, los negros de a pie se iban erigiendo como protagonistas $\mathrm{y}$ «muchas personas pudientes arrojaban dinero á la Plaza para premiar la pericia de los toreros» (Mendiburu, 1902: 88-89), contribuyendo así a su futura profesionalización. El toreo devino entonces en un 
arte propio de la gente de color, lo que obligó a establecer comparaciones con España y concluir que «los toreros españoles no exceden á los negros de Lima» (Fuentes, 1985: 144). ¿En qué momento habrían aparecido entonces los capeadores a caballo en la Plaza de Acho?

Es posible que al principio los negros salieran a cabalgar sin rejones para diferenciarse de los señores y para celebrar corridas bufas, pero al apoderarse de la fiesta pudieron convertir la caricatura en un canon taurino:

«El capeo á caballo consiste en lo siguiente: el ginete se para frente á la puerta por que debe salir el toro, furioso por la prisión estrecha en que se le pone momentos ántes y por habérsele azusado con chuzasos en el instante de abrirse el toril. En ese estado, no bien ha asomado el toro la cabeza, le tiende el toreador la capa y lo llama al centro de la plaza; cuando parece que las astas del toro van á tocar los hijares del caballo, gira éste a la derecha ó á la izquierda, según maneja las riendas el ginete, y el toro da la embestida en vago. Es preciso que el toro tenga mucho aliento para que resista, sin cansarse, seis suertes de á caballo» » (Fuentes, 1985: 142-143).

No cabe ninguna duda con respecto a la identidad de los capeadores, pues, según algunos, «este capeo, peculiar á Lima, quedó en las corridas de toros sólo para hombres de la plebe y asalariados» (Mendiburu, 1902: 90), mientras que para otros «jamás se ha capeado á caballo sino por los negros y zambos hijos del país» (Fuentes, 1985: 142). De cualquier manera, la suerte adquirió denominación de origen, ya que en 1831 Pedro Zavala, marqués de Valle Umbroso, publicó en Madrid su Escuela de Caballería, conforme á la práctica observada en Lima, donde daba a conocer a los aficionados peninsulares las características de esa suerte limeña (Cf. Palma, 1957: 49). 
2.- CONSTRUCCIÓN DE LA PLAZA DE ACHO: MECANISMOS DE CONTROL SOCIAL

Hasta mediados del siglo XVIII, el crecimiento urbano de Lima había sido progresivo y de una franca recuperación con respecto a la fractura demográfica que significó la conquista. Sin embargo, los terremotos funcionaron como freno de esas tendencias. En 1746 un terrible seismo destruyó Lima:

«En cuanto a la población de Lima, en 1746, por los padrones de confesión, se calculaba que vivían en la ciudad y haciendas de sus alrededores unas 60,000 personas. Como el número de víctimas del terremoto se calculó en 6,000, la totalidad de los habitantes era en 1748 de 54,000. D. Pedro José Bravo Lagunas y Castilla, uno de los comisionados por el virrey, en su Voto Consultivo, impreso en el año 1761, dice que en 1755, o sea nueve años después de la ruina, el crecimiento vegetativo no había llegado a cubrir la cifra de los desaparecios» (Vargas Ugarte, 1938: 6).

Aunque la diferencia cronológica es considerable, quizá valga la pena comparar las cifras del censo limeño de 1791 con las del lapso que va de 1746 a 1755 . En 1791 la población se distribuía de la siguiente manera:

\author{
Españoles 18,047 \\ Negros 13,479 \\ Mulatos/Zambos 10,023 \\ Mestizos 4,807 \\ Indios 4,332 \\ Total 50,688 (A.G.L., 1524).
}

Se puede comprobar que la población marginal de Lima (negros, mulatos, mestizos e indios) era claramente 
mayoritaria, de donde desprendemos que el cuadro debe haber sido más o menos el mismo hacia 1746, con el agravante de la miseria añadida por el terremoto. La capital del virreinato era un gigantesco lugar de hacinamiento:

«Dentro del recinto urbano, la población esclava terminaría predominando en las Parroquias de la Catedral y San Lázaro: la primera era en el centro mismo de la ciudad, donde alrededor de la Plaza Mayor se agolpaban tanto las casonas, como callejones y pulperías, lugares verdaderamente tugurizados; la segunda, antiguo arrabal de camaroneros, estaba hacia las afueras, en dirección del camino que salía para Trujillo, entre el río y la recién construida Alameda: área populosa y de visible pobreza» (Flores Galindo, 1984: 101).

Las clases más deprimidas no tuvieron otra alternativa que dedicarse al vagabundaje 6 , lo que alarmaba sobremanera a la ampulosa aristocracia limeña. En 1770 se calculó que el número de vagabundos ascendía a 19,232, cifra que representaba el $40 \%$ de la población total de la ciudad ${ }^{7}$. ¿No es razonable suponer que entre 1746 y 1756 las condiciones debieron ser casi las mismas?

En 1759, Diego Ladrón de Guevara propuso al virrey Amat la construcción de un hospicio para solucionar el problema de los vagabundos:

6 «El vagabundaje urbano era una respuesta muy propia de los mestizos, mulatos, palanganas y españoles o criollos pobres que se dio en las ciudades del Virreinato. Desde el punto de vista económico su hábitat tenía que ser urbano, porque allí estaba el centro de consumo por excelencia donde su ingenio podría inventar una multiplicidad de vías de redistribución que hiciera posible su existencia». Ver Toro (1981: 287-288).

7 "Destino que debe darse á la gente vaga que tiene Lima" (Sociedad de Amantes del País, 1794: 112-132). 
«...se pretendía para erigir en esta ciudad un Hospicio de Pobres mendicantes de ambos sexos, donde recogidos los inbálidos y los que con falso pretexto de necesidad mendigan por las calles su sustento, se mantengan todos y trabajen los que puedan, a proporsión de sus fuersas, en los exercicios que sean útiles, para sostener en parte los costos de la Casa y de su manutensión...» (A.G.I., Lima, 28.I.1766: 968).

No hay que pensar que a Ladrón de Guevara le movía un interés altruista, pues solicitó al virrey terrenos «para la abitación de los pobres de ambos sexos que se han de recoger, como para los exercicios mecánicos a que deben destinarse, y especialmente para el obraxe de ropa de la tierra y lienzos de este país» (A.G.I., Lima, 28.I.1766: 968). Como se puede apreciar, la idea era lucrarse con el trabajo de los pobres.

El virrey Amat no tuvo que pensar mucho para encontrar la fuente de los fondos que acabaría con las tensiones sociales de Lima. Los toros eran un gran negocio, capaz de rendir ganancias inverosímiles:

«Destruido el hospital de San Lázaro por el terremoto de 1746, se hicieron por dos años, en los días de Carnaval, dos corridas de toros. Las cuatro produjeron como cincuenta mil pesos libres, que sirvieron para la reedificación de dicha casa» (Mendiburu, 1902: 86-87).

Así fue como se decidió aceptar la propuesta de Agustín Hipólito de Landaburu $^{8}$, quien había ofrecido construir

8 «Vecino de Lima y alcalde ordinario en 1766 . Proyectó en el siglo pasado el establecimiento de una plaza firme para la lidia de toros, que se hacía antes en la Plaza Mayor, con motivo de fiestas clásicas, y en la plaza de Otero ordinariamente, armándose el circo de una manera portátil con los contratistas»; ver Mendiburu (1933: 405-406). El testamento de Agustín Landaburu se encuentra en el Archivo General de la Nación de Lima, Protocolos de Francisco Luque, 1779 (641), f. 1228 (citado por Lohmann: Los regidores perpetuos..., t. II, p. 159). 
una plaza firme con su propio patrimonio. El virrey comprendió que la renta del coso permitiría construir el hospicio, liberar a la ciudad de vagabundos y entretener a la población. Por eso en un bando de 1765 anunciaba la relación entre ambos proyectos:

«Por quanto el Rey Nuestro Señor, cerciorado de los importantes fines, que se logran, y males, que se evitan, mediante la fábrica de un Hospicio General de Pobres en esta Capital, en el qual á exemplo de lo que se practica en la Corte de Madrid, en muchas ciudades de España, y en inumerables de Europa, se recoxan los ynválidos de ambos sexos, que vagan por las calles, y plazas, á mejorar de vida, costumbres y entretenimiento; se dignó su piedad, por Cédula expedida en Zaragoza a 24 de Noviembre de 1759 dispensar Real permiso, para que en esta ciudad, se erigiese la Casa, que con aquel loable destino pretende levantar D. Diego Ladrón de Guevara, mandando, que este Superior Govierno promueva la construcción de élla, por todos los medios que le sean posibles, hasta dexarla enteramente perfecta y fenecida: en cuyo cumplimiento, por Decreto de 15 del corriente apliqué á este recomendable objeto, mill y quinientos pesos annuales, que por sí, y por sus herederos, se obligó á contribuir D. Agustín de Landaburu, por solemne contrata sobre el permiso de la Plaza firme de toros» (A.G.I., Lima, 20.VI.1765: 968).

En su Memoria de Gobierno Amat repitió que «en estas circunstancias salió proyectando Dn. Augustín de Landaburu, construir á su costa una Plaza firme de toros en que se havían de celebrar ocho corridas al año, bajo de ciertas estipulaciones, ofreciendo dar mil y quinientos pesos anuales al Ospicio de Pobres que se ha erigido» (Mendiburu, 1933: 405406), pero el decreto publicado en Lima en junio de 1765 revela que el virrey tenía otras intenciones ${ }^{9}$.

En efecto, las corridas eran vistas como «un fondo seguro y permanente para ocurrir con promptitud a cualquiera

${ }^{9} \mathrm{El}$ decreto lo transcribiremos al final de este trabajo. 
novedad», y esa fue la coartada de Amat para utilizar las ganancias de la Plaza en «la satisfacción de las cantidades que se están debiendo del costo impendido en la construcción de las pilas de la Alameda de esta ciudad» y en la edificación de «las piezas y oficinas precisas para poder servir de cuarteles a las compañías de mi guardia». Suponemos que Landaburu no puso objeciones, ya que en 1767 el virrey lo recomendó como candidato a la Orden de Santiago ${ }^{10}$.

Sin embargo, ¿existió otra razón de control social más allá de financiar el hospicio donde se pensaba recluir a mendigos y vagabundos? La construcción de una plaza no sólo implicaba ubicar al público en asientos colocados detrás de una barrera, sino impedir la intromisión de los espontáneos, rasgo típico de la conducta de negros e indios durante las corridas. De ahí que el virrey ponderara las ventajas de una plaza firme señalando que era:

«...el medio más poderoso para evitar en los carnavales con esta diversión, los perjudiciales y lastimosos sucesos que se han experimentado, y no han bastado a impedir ni las eficaces providencias de este superior Govierno ni el celo y vigilancia de las justicias que han solicitado su execución y cumplimiento, por cuya causa mis antecesores han procurado siempre que se corran toros en semejantes días, logrando por este medio evitar aquellos inconvenientes...» (A.G.I., Lima, 1765: 968).

No obstante, a pesar de la reacción señorial, los privilegios de la Plaza de Acho y la construcción del metalizado hospicio, la plebe urbana siguió presionando hasta apoderarse por completo de la fiesta, ese atributo aristocrático

10 «A mi secretario, Dn. Martín de Marbiarena y Dn. Agustín de Landáburu propuse por ábitos, ambos lo merecen (AGI, Lima 639: El virrey a S.M., Lima, 25.III.1767). 
reelaborado y asumido por las clases populares. Demás está decir, entonces, que tales maniobras fueron inútiles y que mendigos, vagabundos y delincuentes se multiplicaron, porque en la Plaza los señores pudieron protegerse en la sombra del populacho, y porque los espejismos de armonía duraban lo mismo que la embestida de los toros en una tarde soleada. Después todos volvían a la violencia cotidiana.

\section{APÉNDICE Documental}

Decreto del VirRey Amat y Juniet, otorgando a D. Agustín landaburu la construcción de la Plaza Firme DE ACHO (LIMA, 15 DE JUNIO 1765)

«Decreto Por quanto las fiestas y corridas de toros se han considerado siempre en esta ciudad, no solamente como el expectáculo más grato al mucho vecindario que en sí encierra - lo que dio motivo a que se expidiere por S.M. la Real Cédula en Madrid a diez de Mayo de mil seiscientos cuarenta en que previene al Excmo. Marqués de Mancera que por ningún pretexto se les impidiese en los días que señala_, sino también como el medio más poderoso para evitar en los carnavales con esta diversión, los perjudiciales y lastimosos sucesos que se han experimentado, y no han bastado a impedir ni las eficaces providencias de este superior Govierno ni el celo y vigilancia de las justicias que han solicitado su execución y cumplimiento, por cuya causa mis antecesores han procurado siempre que se corran toros en semejantes días, logrando por este medio evitar aquellos inconvenientes y atender igualmente al reedificio de algunas Yglessias y hospitales, que con el producto de las corridas han conseguido su entera perfección, y que se restablescan algunas obras públicas que sirvan a la hermosura y subsistencia de la ciudad. Lo que ha hecho considerar este producto como un fondo seguro y permanente para ocurrir con promptitud a qualquiera novedad y reconocer en conformidad y unión todas las leyes y distribuciones a que deben arreglarse, demás de los muchos 
ynconvenientes que resultan de que cada uno viva separadamente en las distancias que les ofrece su proporción y comodidad. Por tanto, para ocurrir a todas estas importantísimas causas y a la satisfacción de las cantidades que se están debiendo del costo impendido en la construcción de las pilas de la Alameda de esta ciudad, que por otro medio se haría impracticable, teniendo en quenta la propuesta hecha por parte de don Agustín de Landaburu, que ofrece construir una plaza o coso de firme en que se puedan correr toros annualmente y en conformidad de lo pedido por el señor fiscal a la vista que se le dio y de los Ynformes del Cabildo, Justicia y Regimiento de esta ciudad, le concedo al referido don Agustín la licencia que solicita, para que pueda fabricar en el sitio nombrado el Acho, la plaza de firme que ha propuesto para que haga correr en ella toros ocho veces al año en otros tantos días, entendiéndose que cinco de ellos han de verificarse en los tres del carnaval y los dos jueves que le anteceden, y los tres restantes a los seis meses de este tiempo en los más proporcionados y propios a estas fiestas, y con las calidades y condiciones siguientes: que todo el importe de su fábrica lo ha de costear el dicho don Agustín, como también el de las piezas y oficinas precisas para poder servir de cuarteles a las compañías de mi guardia, las que deberán construirse en los contornos de la dicha plaza, para que puedan aplicarse a tiendas públicas o bodegones en que socorran con comodidad los que asistiesen a ellas, percibiendo para sí el dicho don Agustín el producto de los alquileres de las referidas piezas por aquel tiempo, como así mismo, todo el que rindiesse la paga de los asientos que han de servir a los espectadores y las demás utilidades que por qualquiera razón pudiesen producir las corridas que ha de costear en todas sus partes el dicho don Agustín, que por esta causa se obligará a enterar en estas Reales Caxas todos los años concluidas las últimas de cada uno, la cantidad de un mil y quinientos pesos que desde ahora se aplican a la contribución, fomento y absistencia del Hospicio de Pobres que se ha de fabricar en la conformidad que lo ha propuesto don Diego Ladrón de Guevara.

»Y assí mismo se obligará a enterar el importe de la cantidad que se está debiendo del costo impendido en las pilas de la Alameda, en la forma y por los términos y plazos que constarán por ynstrumento separado que sobre la razón se ha de otorgar.

»Que concluida enteramente la obra de la Plaza y cuarteles se ha de tasar ésta por dos peritos, uno de los quales nombrarán los Oficiales Reales de estas Cajas y el otro el referido don Agustín, y de su monto 
unido al importe del crédito de las pilas, se rebajará annualmente la cantidad de mil pesos. Y corridos los años bastantes para descontarse una y otra, quedará la obra enteramente para beneficio de Su Magestad, en cuyo Real nombre -desde ahora para entonces- la aplico con todas sus utilidades y aprovechamientos al referido Hospicio General de los Pobres de ambos sexos, con la calidad de traher aprovación del Rey.

»Que en caso de tenerse por conveniente sacarse a remate por entonces la administración de este ramo, será preferido por él tanto el dicho don Agustín o sus albaceas o herederos, con quienes correrán igualmente los capítulos de la contrata que ahora deberá otorgarse sin novedad alguna, caso que el dicho don Agustín fallezca antes que haya corrido el tiempo preciso para descontarse el importe de la obra y paga de las pilas en la forma arriba expresada, los quales no se le rebajarán enteramente.

»El año que por algún motivo o razón a que no dé causa el dicho don Agustín, no se corriesen toros en los ocho días que se le han concedido, deviendo ser la rebaja a proporción de los que se verificasen como también el entero de los mil y quinientos pessos annuales, sino se corriesen ni aún los días a que pueda corresponder en prorrata esta erogación, concediéndosele en este evento facultad al maiordomo, síndico y administrador del Hospital General, para que si a su riesgo quiere fomentar las corridas annuales con tal que no sean más en número de las estipuladas, pueda hacerlo reportando íntegramente las utilidades a beneficio de la casa.

»Y para que el dicho don Agustín pueda con maior desaogo (y facultad) -digo- facilidad, prevenir el número de toros necesarios a las ocho corridas y evitar al mismo tiempo los inconvenientes que se han tenido presentes y resulta de que éstos se jueguen en los contornos de esta ciudad, donde se hace difícil enviar las debidas precauciones para impedir perjudiciales consecuencias, mando que por ningún pretexto ni motivo puedan correrse éstos en los referidos contornos a la distancia de ocho leguas, bajo las penas arbitrarias de este superior gobierno en caso de contravención, reservándole al dicho don Agustín su derecho a salbo para que pida por entonces lo que le convenga.

»Y respecto de haberse considerado preciso el nombramiento de un señor ministro de esta Real Audiencia, que como juez de estas funciones y sin perjuicio de la juridiscción de los alcaldes ordinarios conozca privativamente de todas sus incidencias y a quien pueda ocurrir el referido don Agustín por las providencias necesarias, no solamente para el efecto de las corridas, sino también para las que le 
parecieren convenientes durante la construcción de la obra, se hará el referido nombramiento por decreto separado, en que se le señalará específicamente la jurisdicción y facultades que se le concedan.

»Y para que todo tenga más debido y efectivo cumplimiento y no se ofrezca en lo subcedido tropiezo o embargo sobre la obligación respectiva a dicho don Agustín, o sobre las calidades y condiciones conque se le ha concedido la licencia, los Oficiales Reales -a quienes se les pasará original del decreto- procederán a otorgar el ynstrumento correspondiente con la parte del dicho don Agustín, insertándolo a la letra y no omitiendo expresión o cláusulas que puedan conducir a precaver en todo tiempo las dificultades que suele ocasionar la variación de circunstancias, tomándose razón antes en el libro de órdenes y vandos. Lima, quince de junio de mil setecientos sesenta y cinco.

»El Virrey del Perú, don Manuel de Amat y Juniet [rubricado]» [AGI, Lima 968]. 


\section{BIBLIOGRAFÍA}

Archivo General de Indias (15-V-1564): Lima 121, Carta de Nicolás de Ribera a S. M.

S.M.

(1571): Lima 28-A, Carta del virrey Toledo a Loayza a S.M.

(23-IV-1572): Lima 300, Carta del Arzobispo

Yndias a S.M., Madrid.

Lohmann, G. (1983): Los regidores perpetuos del Cabildo de Lima (1535-1821), Sevilla, Publicaciones de la Excma. Diputación Provincial de Sevilla, t. II.

Fuentes, M. A. (1985): Lima. Apuntes históricos, estadísticos, administrativos, comerciales y de costumbres, París, Librería de Firmin Didot hermanos (1867) [edición facsimilar del Banco Industrial del Perú, 1985].

Iwasaki, F. (1989): El comercio ambulatorio en Lima, Lima, Instituto Libertad y Democracia.

(1987): "El pensamiento de Pablo de Olavide y los ilustrados peruanos", en Histórica XI-2, Lima, Pontificia Universidad Católica del Perú.

Mendiburu, M. de (1902): Apuntes históricos, Lima, Imprenta del Estado.

Mugaburu, J. (1935): Diario de Lima (1640-1694), transcripción y edición de Carlos A. Romero, Lima, Imprenta Casa Vázquez.

Palma, R. (1957): Tradiciones Peruanas, Madrid, Aguilar. 
Parry, J. H. (1970): El imperio español de ultramar.

Sociedad de Amantes del País: "Destino que debe darse á la gente vaga que tiene Lima", en Mercurio Peruano, t. X, Lima.

Suardo, J. A. (Lima, 1938): Diario de Lima (16291634), edición y transcripción de Rubén Vargas Ugarte S. J., Lima, Imprenta Casa Vázquez. 